\title{
The Characteristics of Industrial Accidents in Shipbuilding Industry
}

\author{
Kyung Tae Lee \\ Department of Management, Daebul University, Youngam-gun, 526-702
}

\begin{abstract}
Objective: The aim of this study is to investigate the characteristics of industrial accidents in shipbuilding industry. Background: As the accident frequency in shipbuilding industry is higher than those of other industries, it is important to grasp the accident characteristics of shipbuilding industry to reduce the accidents. Method: This paper aggregated some important accident report of the shipbuilding industry including industrial accident analysis of Korean government and drew some important accident characteristics of shipbuilding industry. Results: Accidents in Shipbuilding industry was reviewed in respect of accidents rate, accidents distribution by age, accidents by employed period, accidents severity, accidents type, accidents type by process, accidents caused by object, and hazards in process. Conclusion: Accident related indexes in shipbuilding were much higher than those of whole industry. Application: These results can be used to provide base information for more effective accident preventions in shipbuilding industry.
\end{abstract}

Keywords: Industrial accidents, Shipbuilding industry

\section{Introduction}

산업재해의 특성을 조사하는 것은 산업재해의 원인을 파 악하고 이를 체계적으로 관리하여 궁극적으로 재해의 위험 을 감소시키려는 목적을 갖는다. 조선업(업종구분에 따르면 선박건조 및 수리업으로 분류된다)은 2009년을 기준으로 451억 달러를 수출하여 우리나라 수출 상위 품목 1 위를 차 지할 정도로 성장하였다(Ministry of Knowledge Economy, 2009). 그러나 재해 현황을 살펴보면 조선업 재해율은 최근 5년 평균 $1.20 \%$ 로서 전체산업 재해율 $0.69 \%$ 보다 현저히 높을 뿐만 아니라, 제조업 전체 재해율 $1.06 \%$ 에 비해서도 높은 편이다(Ministry of Employment and Labor, 2010).

2010년도를 기준으로 조선업 규모별 사업장 현황을 보면 Table 1 과 같다. 표에서 보는 바와 같이 50 인 이하의 소규 모 사업장은 총 4,241 개소에서 39,672 명이 근로하고 있으 며 재해건수는 1,126 건으로 전체의 $53.0 \%$ 를 차지하고 있
다. 특히 50 인 이하 사업장의 재해율 $(2.25 ~ 8.14 \%)$ 은 50 인 이상의 사업장의 재해율 $(0.67 \sim 1.2 \%)$ 에 비해 큰 차이를 보 인다.

조선업의 일반적인 공정은 Figure 1 과 같이 분류할 수 있 다(Shipbuilding Terminology Dictionary, 1997).

원자재 입고 - 적치는 육로나 해상을 통하여 강판이나 형 강을 크레인 등으로 적치장에 하역하는 공정이다.

절단 · 가공 공정은 크레인으로 강판을 컨베이어에 적재하 고 표면을 가열하여 수분, 녹 등을 제거하며 녹방지를 위해 표면을 코팅한 후 건조설비에서 건조하고, 강판을 크레인 등 으로 절단정반에 운반하여 자동절단기로 용도별로 절단한 후, 프레스 등으로 곡 또는 굽힘가공을 하고, 이를 토치작업을 통하여 굽힘응력을 제거하는 공정이다.

소 · 중조립은 소부재를 크레인 등으로 운반하여 조립장에 서 취부 - 용접 - 사상작업을 거쳐 조립하는 공정이다.

대조립은 소 · 중조립된 블록을 크레인 등으로 운반한 후 핀지그 정반 등에 주판 블록을 적치한 후 용접기 등으로 취

Corresponding Author: Kyung Tae Lee. Department of Management, Daebul University, Jeonnam, 526-702.

Mobile: 010-8101-000, E-mail: ktlee@db.ac.kr

Copyright@2012 by Ergonomics Society of Korea(pISSN:1229-1684 eISSN:2093-8462). All right reserved. 
부 - 용접 - 사상작업을 거쳐 대블록 단위로 만드는 공정이다.

도장 공정은 대블록을 트랜스포터 등으로 운반하여 블라 스팅 공장에서 쇼트볼로 녹을 제거한 후 도장 공장에서 도 장을 한다.

의장 공정은 선박 부속물(지지물, 배관, 전기케이블 등)을 운반하여 블록 구조물에 부착하는 공정이다.

탑재 공정은 대블록을 트랜스포터로 도크 근처로 운반한 후 골리앗 크레인으로 도크 내부로 옮겨 여러 개의 대블럭을 취부 - 용접 - 사상작업 등을 거쳐 하나의 배로 만드는 공정 이다. 이 공정에서 블록의 내·외부 도장작업도 수행된다.

진수 공정은 선박을 도크에서 해상으로 진수하는 공정으 로 진수 후 안벽으로 옮겨 주요 구조물을 부착한다.

시운전은 배 완성 후 전기장치, 계측장치 등의 문제점을 수정 - 보완하고 건조된 배의 성능을 테스트하고 청소 및 터 치업 도장을 하는 공정이다.

본 연구의 목적은 우리나라의 조선소에서 발생하는 산업 재해의 전반적인 특성과 공정별 산업재해의 특성을 파악하 는 것이다. 이는 조선소에서 재해예방을 하는데 기초자료로 활용될 수 있을 것이다.

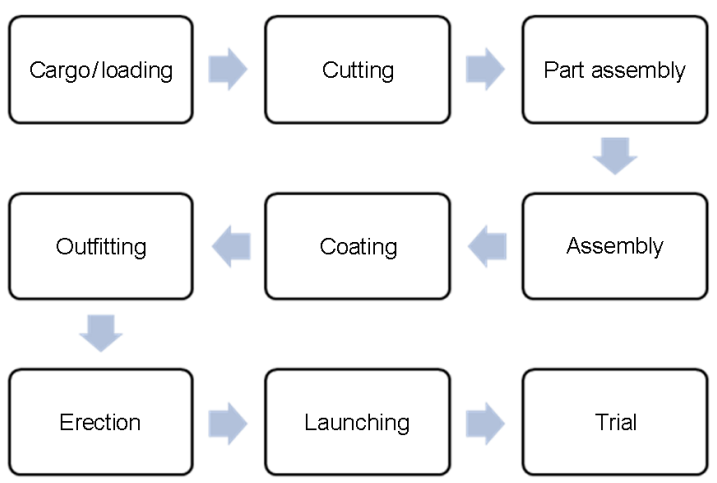

Figure 1. Shipbuilding process

\section{Method}

본 연구는 국내의 조선업종 재해 통계와 조선업 관련 문헌 조사 결과를 바탕으로 조선소에서 발생하는 재해 형태를 재 정리하고 해석하는 방법으로 진행하였다. 먼저 노동부에서 매년 발간하는 산업재해분석보고서를 2001년부터 2010년 까지 조사한 후 조선업에 관련된 자료만을 추출하여, 조선업 의 재해 특성을 연도별, 연령별, 근무기간별, 재해심각도별, 재해 형태별, 공정별, 기인물에 따라 재정리하고 해석하였다
(Ministry of Employment and Labor, 2001-2010). 또한 조선업은 규모가 방대하고 조업밀집도가 높아 공정별로 다 양한 사고 요인이 잠재되어 있다(Kim et al., 2011). 따라서 Table 1 의 공정순서에 따라 각 공정에 잠재되어 있는 주요 유해 · 위험성을 요약하였다(Development of Audit Model for the Result of Hazard Assessment in Shipbuilding Industry, 2008).

Table 1. The state of shipbuilding company (Ministry of Employment and Labor, 2010)

\begin{tabular}{c|c|c|c|c|c}
\hline Size & $\begin{array}{c}\text { No. of } \\
\text { company }\end{array}$ & $\begin{array}{c}\text { No. of } \\
\text { employee }\end{array}$ & $\begin{array}{c}\text { No. of } \\
\text { accident }\end{array}$ & $\begin{array}{c}\text { No. of } \\
\text { fatality }\end{array}$ & $\begin{array}{c}\text { Accident } \\
\text { rate }\end{array}$ \\
\hline $\begin{array}{c}1 \sim 5 \\
\text { person }\end{array}$ & $\begin{array}{c}2,070 \\
(41.9 \%)\end{array}$ & $\begin{array}{c}3,968 \\
(2.2 \%)\end{array}$ & $\begin{array}{c}323 \\
(15.2 \%)\end{array}$ & $\begin{array}{c}6 \\
(12.8 \%)\end{array}$ & 8.14 \\
\hline $\begin{array}{c}5 \sim 49 \\
\text { person }\end{array}$ & $\begin{array}{c}2,171 \\
(43.9 \%)\end{array}$ & $\begin{array}{c}35,704 \\
(20.1 \%)\end{array}$ & $\begin{array}{c}803 \\
(37.8 \%)\end{array}$ & $\begin{array}{c}14 \\
(29.8 \%)\end{array}$ & 2.25 \\
\hline $\begin{array}{c}50 \sim 299 \\
\text { person }\end{array}$ & $\begin{array}{c}681 \\
(13.8 \%)\end{array}$ & $\begin{array}{c}71,976 \\
(40.6 \%)\end{array}$ & $\begin{array}{c}479 \\
(22.6 \%)\end{array}$ & $\begin{array}{c}18 \\
(38.3 \%)\end{array}$ & 0.67 \\
\hline $\begin{array}{c}300 \\
\text { person } \sim\end{array}$ & $\begin{array}{c}16 \\
(0.003 \%)\end{array}$ & $\begin{array}{c}65,785 \\
(37.1 \%)\end{array}$ & $\begin{array}{c}517 \\
(24.4 \%)\end{array}$ & $\begin{array}{c}9 \\
(19.1 \%)\end{array}$ & 0.79 \\
\hline Sum & $\begin{array}{c}4,938 \\
(100.0 \%)\end{array}$ & $\begin{array}{c}177,433 \\
(100.0 \%)\end{array}$ & $\begin{array}{c}2,122 \\
(100.0 \%)\end{array}$ & $\begin{array}{c}47 \\
(100.0 \%)\end{array}$ & 1.20 \\
\hline
\end{tabular}

\section{Results}

앞 절의 방법에 따라 각 항목별 사고 특성을 요약하고 해 석하면 다음과 같다.

\subsection{Recent accident rate}

최근 5 년간 산업전체의 재해율과 조선업 재해율을 비교 하면 Figure 2와 같다. 최근 5년간 산업전체의 재해율은 $0.72 \%$ 이고 조선업의 재해율은 $1.56 \%$ 로 조선업의 재해율 이 최근 감소되고 있기는 하지만 여전히 전체산업 재해율의 2 배 이상을 차지하고 있다.

최근 5년간 조선소 규모에 따른 재해율을 조사하였다 (Table 2), 특이한 점은 회사 규모가 작을수록 재해율이 높 다는 점이다. 이는 소규모 회사일수록 체계적인 안전관리시 스템이 잘 가동되고 있지 않기 때문으로 해석할 수 있다. 특 히 5인 이하 사업장의 재해율은 8.14 11.21\%로 매우 높다.

\subsection{Accident distribution by age}

2010년의 전체산업과 조선업의 재해분포를 연령대별로 


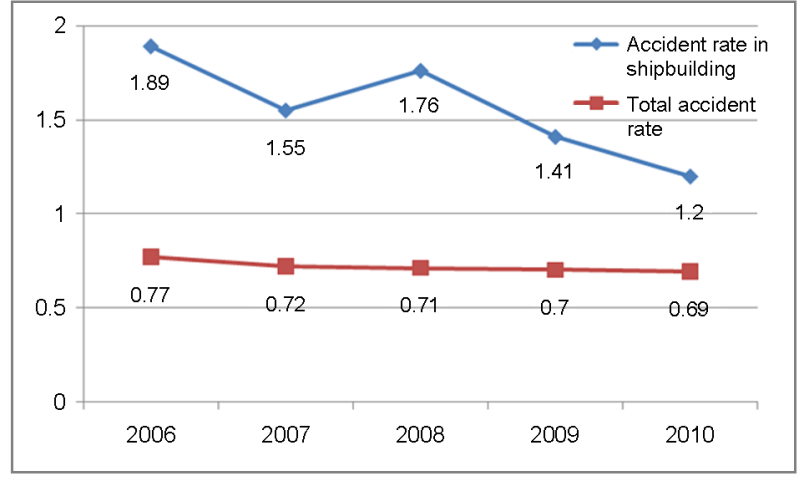

Figure 2. Recent accident rate(\%)

Table 2. Accident rate by company size(2006 2010)

\begin{tabular}{c|r|r|r|r|c}
\hline $\begin{array}{c}\text { Company } \\
\text { size(man) }\end{array}$ & 2006 & 2007 & 2008 & 2009 & 2010 \\
\hline Below 5 & $11.21 \%$ & $10.03 \%$ & $9.46 \%$ & $11.15 \%$ & $8.14 \%$ \\
\hline $5 \sim 49$ & $3.14 \%$ & $3.42 \%$ & $2.84 \%$ & $2.59 \%$ & $2.25 \%$ \\
\hline $50 \sim 299$ & $1.19 \%$ & $0.90 \%$ & $0.94 \%$ & $0.79 \%$ & $0.67 \%$ \\
\hline Above 300 & $1.60 \%$ & $1.27 \%$ & $1.41 \%$ & $0.87 \%$ & $0.79 \%$ \\
\hline Total & $1.89 \%$ & $1.55 \%$ & $1.76 \%$ & $1.41 \%$ & $1.20 \%$ \\
\hline
\end{tabular}

조사하면 Table 3 와 같다. 조선업의 경우는 30 대에서 상대 적으로 높은 재해분포를 갖고 50 대 이상에서는 상대적으로 낮은 재해분포를 보이고 있다.

\subsection{Accident distribution by the employed period}

2010년의 전체산업과 조선업의 재해발생을 근무기간별로 조사하면 Table 4 와 같다. 산업전체와 조선업간의 큰 차이
는 발견되지 않으나, 특이한 점은 조선업이나 산업전체 모 두에서 근무기간이 6 개월 미만인 경우가 총 재해의 각각 $54.25 \%, 49.67 \%$ 를 차지한다는 점이다. 이는 아직 업무에 익숙하지 않은 근로자가 대부분의 재해를 일으키는 전형적 인 특징을 보여주고 있다.

\subsection{Accident severity}

2010년의 전체산업과 조선업에서 발생한 재해강도를 의 학적 치료기간에 따라 조사해 보면 Table 5와 같다. 특이한 점은 조선업의 경우 재해 후 치료기간이 180 일 이상인 비율 이 $31.67 \%$ 로 전체산업 평균 $17.00 \%$ 에 비하여 현저히 높 다. 이는 조선업종의 노동강도가 높아 의학적 치료기간이나 재활기간이 많이 필요하다고 해석할 수 있다.

\subsection{Accident type}

2010년을 기준으로 전체산업과 조선업에서 발생한 재해 형태 중 상위 5 개를 각각 조사하였다(Table 6). 전체산업의 경우 상위 5 위를 차지하는 재해 형태는 전도 $(21.53 \%)$, 협착 (17.11\%), 추락(14.23\%), 충돌 $(8.78 \%)$, 절단 $(8.09 \%)$ 순 이다. 조선업의 경우 상위 5 위를 차지하는 재해 형태는 추락 (19.93\%), 전도(17.72\%), 협착(11.07\%), 충돌(10.79\%), 낙하/비래 (10.56\%) 순이다.

조선업의 특성상 고소작업이 많아 추락이 1순위를 차지하 고 있는 것을 알 수 있다. 특히 추락은 중대재해로 이어지는 경우가 많아 이에 대한 조치가 필요하다고 할 것이다.

\subsection{Accident type by process}

공정별 재해발생 현황은 Table 7 에 조사되어 있다(The

Table 3. Accident distribution by age(2010)

\begin{tabular}{c|c|c|c|c|c|c|c}
\hline & Below 18 & $18 \sim 29$ & $30 \sim 39$ & $40 \sim 49$ & $50 \sim 59$ & Above 60 & Total \\
\hline Whole industry & $0.18 \%$ & $10.46 \%$ & $18.81 \%$ & $27.36 \%$ & $28.72 \%$ & $14.47 \%$ & $100.00 \%$ \\
\hline Shipbuilding & $0.00 \%$ & $9.43 \%$ & $26.67 \%$ & $27.51 \%$ & $25.63 \%$ & $10.74 \%$ & $100.00 \%$ \\
\hline
\end{tabular}

Table 4. Accident distribution by the employed period(2010)

\begin{tabular}{c|c|c|c|c|c|c|c|c|c|c}
\hline Employed period & $\begin{array}{c}\text { Below } \\
0.5 \mathrm{yr}\end{array}$ & $0.5 \sim 1 \mathrm{yr}$ & $1 \sim 2 \mathrm{yr}$ & $2 \sim 3 \mathrm{yr}$ & $3 \sim 4 \mathrm{yr}$ & $4 \sim 5 \mathrm{yr}$ & $5 \sim 10 \mathrm{yr}$ & $\begin{array}{c}\text { Above } \\
10 \mathrm{yr}\end{array}$ & $\begin{array}{c}\text { Not } \\
\text { classified }\end{array}$ & $\begin{array}{c}\text { Total } \\
\text { Classification }\end{array}$ \\
\hline $\begin{array}{c}\text { Whole } \\
\text { industry }\end{array}$ & $\begin{array}{c}53,511 \\
(54.25 \%)\end{array}$ & $\begin{array}{c}9,989 \\
(10.13 \%)\end{array}$ & $\begin{array}{c}9,279 \\
(9.41 \%)\end{array}$ & $\begin{array}{c}5,428 \\
(5.50 \%)\end{array}$ & $\begin{array}{c}3,443 \\
(3.49 \%)\end{array}$ & $\begin{array}{c}2,491 \\
(2.53 \%)\end{array}$ & $\begin{array}{c}6,807 \\
(6.90 \%)\end{array}$ & $\begin{array}{c}7,039 \\
(7.14 \%)\end{array}$ & $\begin{array}{c}658 \\
(0.67 \%)\end{array}$ & $\begin{array}{c}98,645 \\
(100.00 \%)\end{array}$ \\
\hline Shipbuilding & 1,054 & 186 & 171 & 98 & 77 & 40 & 119 & 353 & 24 & 2,122 \\
$(19.67 \%)$ & $(8.77 \%)$ & $(8.06 \%)$ & $(4.62 \%)$ & $(3.63 \%)$ & $(1.89 \%)$ & $(5.61 \%)$ & $(16.64 \%)$ & $(1.13 \%)$ & $(100.00 \%)$ \\
\hline
\end{tabular}


Table 5. Accident distribution by the period of medical treatment(2010)

\begin{tabular}{c|c|c|c|c|c|c|c|c}
\hline Period & Death & $\begin{array}{c}\text { Above } \\
180 \text { days }\end{array}$ & $\begin{array}{c}91 \sim 180 \\
\text { days }\end{array}$ & $\begin{array}{c}29 \sim 90 \\
\text { days }\end{array}$ & $\begin{array}{c}15 \sim 28 \\
\text { days }\end{array}$ & $\begin{array}{c}8 \sim 14 \\
\text { days }\end{array}$ & $\begin{array}{c}4 \sim 7 \\
\text { days }\end{array}$ & $\begin{array}{c}\text { Total } \\
\text { Classfication }\end{array}$ \\
\hline $\begin{array}{c}\text { Whole } \\
\text { industry }\end{array}$ & $\begin{array}{c}2,200 \\
(2.23 \%)\end{array}$ & $\begin{array}{c}16,773 \\
(17.00 \%)\end{array}$ & $\begin{array}{c}29,719 \\
(30.13 \%)\end{array}$ & $\begin{array}{c}36,586 \\
(37.09 \%)\end{array}$ & $\begin{array}{c}8,237 \\
(8.35 \%)\end{array}$ & $\begin{array}{c}2,854 \\
(2.89 \%)\end{array}$ & $\begin{array}{c}2,276 \\
(2.31 \%)\end{array}$ & $\begin{array}{c}98,645 \\
(100.00 \%)\end{array}$ \\
\hline Shipbuilding & $\begin{array}{c}47 \\
(2.21 \%)\end{array}$ & $\begin{array}{c}672 \\
(31.67 \%)\end{array}$ & $\begin{array}{c}658 \\
(31.01 \%)\end{array}$ & $\begin{array}{c}490 \\
(23.09 \%)\end{array}$ & $\begin{array}{c}107 \\
(5.04 \%)\end{array}$ & $\begin{array}{c}30 \\
(1.41 \%)\end{array}$ & $\begin{array}{c}118 \\
(5.56 \%)\end{array}$ & $\begin{array}{c}2,122 \\
(100.00 \%)\end{array}$ \\
\hline
\end{tabular}

Table 6. Top 5 accident types in shipbuilding and whole industry(2010)

\begin{tabular}{c|c|c|c|c|c|c|c}
\hline \multicolumn{4}{c|}{ Whole industry } & \multicolumn{4}{c}{ Shipbuilding } \\
\hline Ranking & Accident type & Cases & $\%$ & Ranking & Accident type & Cases & $\%$ \\
\hline 1 & Tripping & 21,242 & $21.53 \%$ & 1 & Falls of person & 423 & $19.93 \%$ \\
\hline 2 & Narrowness & 16,881 & $17.11 \%$ & 2 & Tripping & 376 & $17.72 \%$ \\
\hline 3 & Falls of person & 14,040 & $14.23 \%$ & 3 & Narrowness & 235 & $11.07 \%$ \\
\hline 4 & Collision & 8,663 & $8.78 \%$ & 4 & Collision & 229 & $10.79 \%$ \\
\hline 5 & Cut & 7,979 & $8.09 \%$ & 5 & Falling/flying object & 224 & $10.56 \%$ \\
\hline Others & & 29,840 & $30.26 \%$ & Others & & 635 & $29.92 \%$ \\
\hline Total & & 98,645 & $100.00 \%$ & Total & & 2,122 & $100.00 \%$ \\
\hline
\end{tabular}

Table 7. Accident type by process

\begin{tabular}{c|c|c|c|c|c|c|c}
\hline Process & Processing, assembly & Support & Outfitting & Coating & Erection & Others & Total \\
\hline Cases & 315 & 166 & 145 & 121 & 90 & 265 & 1,102 \\
\hline$\%$ & $28.6 \%$ & $15.1 \%$ & $13.2 \%$ & $11.0 \%$ & $8.2 \%$ & $24.0 \%$ & $100.0 \%$ \\
\hline
\end{tabular}

Table 8. Accident caused by object

\begin{tabular}{c|c|c|c|c|c|c|c}
\hline Cause & Work environment & Block material & Scaffold, staging & Crane & Welder & Others & Total \\
\hline Cases & 293 & 215 & 136 & 55 & 38 & 363 & 1,102 \\
\hline$\%$ & $26.6 \%$ & $19.5 \%$ & $12.3 \%$ & $5.0 \%$ & $3.4 \%$ & $32.9 \%$ & $100.0 \%$ \\
\hline
\end{tabular}

present state of accident and hazardous and dangerous factors in shipbuilding process, 2006).

5 대 재해 다발 공정을 살펴보면 가공조립 $(28.6 \%)$, 지원 (15.1\%), 의장 $(13.2 \%)$, 도장 $(11.0 \%)$, 탑재 $(8.2 \%)$ 순으로 나타났다.

조선업은 고정위치 배치로 그 특성상 공정 자동화가 어렵 다는 특징을 가지고 있다. 위 상위 5 개 공정도 자동화가 어 려운 공정으로 재해 관리가 쉽지 않다는 특성을 가지고 있 다. Table 7 에서 기타 공정이란 선박건조 공정과 연관된 검사, 작업보조 및 준비단계 또는 정리정돈 등의 공정을 말 한다.

\subsection{Accidents caused by object}

재해발생 기인물 상위 5위는 Table 8에 나와 있다. Table 8 에서 보는 바와 같이, 재해발생 기인물 상위 5 개는 작업환 경 $(26.6 \%)$, 선박부재 및 블록(19.5\%), 비계(12.3\%), 크래 인(5.0\%), 용접기(3.4\%) 순으로 나타났다(The present state of accident and hazardous and dangerous factors in shipbuilding process, 2006). 이런 기인물로 인해 추락, 전도, 협착, 충돌, 낙하/비래 등의 재해 형태가 발생한다.

\subsection{Hazards in process}

조선업은 작업자, 도구, 설비, 제품(배)이 한 장소에서 다 
양한 형태로 조합을 이루어 작업이 이루어지므로 각 공정 (Figure 1) 별로 다양한 유해위험요인이 존재한다. 각 공정에 존재하는 유해위험요인을 요약하면 다음과 같다(Development of Audit Model for the Result of Hazard Assessment in Shipbuilding Industry, 2008).

입고/적치 공정에서는 야적장 출입 시 강재와의 충돌 및 협착 위험, 운반장비 (크레인, 컨베이어, 지게차, 트럭)와의 충돌 및 협착 위험, 강재 하역작업 시 전도 및 붕괴 위험, 이 송 중 근로자 출입 시 협착 및 전도 위험 등이 대표적이다.

가공/절단 공정에서는 마그네트 철판 운반 시 낙하 위험, 각종 철판 및 강재 이송 시 충돌/전도/협착 위험, 절단기와 레일 사이 협착 위험, 파렛트 운반 시 낙하 위험, 클램프 이 탈 시 낙하 위험, 절단기 및 용접기의 유해광선과 흠 노출 위험 등이 대표적이다.

소 · 중조립 공정에서는 적재 또는 파렛트 운반 시 낙하 위험, 각종 부재간 충돌 및 협착 위험, 소부재 인력 운반 시 근골격질환 위험, 수직부재 취부 시 전도 위험, 레바/체인블 록 후크 비래 위험, 가용접 불량 시 낙하 및 협착 위험, 유해 광선 및 흠 노출 위험 등이 대표적이다.

대조립 공정에서는 비계 설치 및 해체작업 시 추락 위험, 사다리 및 고소작업 시 추락 위험, 마그네트 크레인 사용 시 낙하 위험, 갠트리 크레인 협착 위험, 각종 블록 충돌 및 전 도 위험, 부재 낙하 - 전도 위험, 가스 누출에 의한 화재 및 폭발 위험, 전기설비 감전 위험, 트랜스포터와의 충돌 위험, 소음 및 용접 흠 노출 위험 등이 대표적이다.

도장 공정에서는 도장 공장 및 믹싱룸 내 화재 및 폭발 위험, 블록 스프레이 및 붓도장 작업 시 화재 위험, 도장 공 장 내 사상작업 시 화재 위험, 비방폭형 전기설비(작업 등 등) 사용 시 화재 및 폭발 위험, 유기용제 노출 및 화재 위 험, 밀폐 블록 내 출입 시 질식 위험 등이 대표적이다.

의장 공정에서는 블록 상부 고소작업 시 추락 위험, 레바 블록/체인블록 사용 시 비래 및 전도 위험, 각종 파이프 지 지대 불량 시 블록 전도 위험, 사다리 전도 및 추락 위험, 용 접기 등 감전 위험, 사상작업 시 연삭칩 비산 및 수지 절상 위험, 용접/사상 작업 시 용접흠 및 분진비산 노출 위험, 고 압 공기압 장비 사용 시 말림 및 소음 노출 위험, 정리정돈 및 통로 미확보 시 협착/충돌/전도 위험 등이 대표적이다.

탑재 공장에서는 크레인 운반 시 샤클/러그 불량에 의한 낙하 위험, 블록 전도 위험, 샤클 체결/해체 시 추락 위험, 러그/와이어/크레인 작업 시 블록 낙하 위험, 고소차 사용 시 충돌/추락/협착 위험, 블록 지지필러 설치 불량 시 전도 위험, 곤도라/고소차/승강사다리 사용 시 전도, 추락 및 낙하 위험, 맨홀 등 개구부 추락 위험, Hatch Coaming 등 이동 시 추락 위험, 비계 설치/해체 작업 중 추락 위험, 레바블록 /유압쟈키 사용 시 비래 및 협착 위험, 전기설비 사용 시 감
전 위험, 밀폐공간 내 용접작업 시 질식 및 화재·폭발 위험 등이 대표적이다.

진수 및 시운전 공정에서는 진수의장 시 사용되는 크레인, 용접기, 도장 $\mathrm{M} / \mathrm{C}$, 수공구 및 고소작업 등에 의한 협착, 충돌, 낙하 - 비래, 추락, 감전, 화재 - 폭발 위험 등이 대표적이다.

\section{Conclusion}

본 논문은 조선업의 재해자료를 문헌을 통하여 조사하고 이를 재구성하여 여러 지표로 조선업의 재해 특성을 파악하 였다.

먼저 전체산업과 조선업의 재해율을 비교하였다. 조선업 재해율은 전체산업 재해율의 2 배 이상에 이르고 특히 소규 모의 조선소에서는 $10 \%$ 대의 높은 재해율을 보이고 있다.

연령별로는 30 대 조선업 근로자의 경우 상대적으로 높은 재해율을 보이고 있다.

근무기간별로는 근무기간 6 개월 미만의 근로자가 조선업 재해의 $49.6 \%$ 를 차지하고 있으므로 근무 초기의 재해를 줄이기 위하여 현장직무교육을 강조할 필요가 있다고 판단 된다.

조선업의 경우 재해 후 180 일 이상의 장기간 의학적 치료 를 하고 있는 비율이 $31.6 \%$ 로 전체산업의 $17.0 \%$ 보다 현저 히 높아 이에 대한 대책도 필요하다고 할 수 있다.

조선업의 경우 상위 5 위를 차지하는 재해 형태는 추락, 전 도, 협착, 충돌, 낙하/비래이다. 특히 추락은 중대재해로 이어 지는 경우가 많아 이에 대한 대책이 필요하다고 할 것이다.

공정별로 재해가 많이 발생하는 순서는 가공조립, 지원, 의장, 도장, 탑재 순이다. 이들 모두 조선업 특성상 자동화가 어려운 공정으로 재해 관리가 쉽지 않다는 특성을 가지고 있다.

재해발생 기인물 상위 5 위는 작업환경, 선박부재 및 블록, 비계, 크래인, 용접기 순으로 나타났다. 이 외에도 조선업 내 에 잠재되어 있는 주요 유해위험요인들을 공정별로 요약하 였다.

본 논문은 다양한 자료로부터 조사된 결과를 바탕으로 재 구성하여 분석한 것이다. 따라서, 수집한 기존 자료의 조사 목적, 조사 시점, 조사 기준이 모두 일관된다고 보기는 어려 우므로 이를 바탕으로 재구성한 결과가 해석상의 한계는 있 겠지만, 본 논문에서 분석된 재해 특성은 조선업의 재해율을 낮추는 데 기초자료로 활용될 수 있을 것이다. 


\section{References}

Kim, Y. C., Jung, H. W. and Bae, C. H., "Prevention of Human Error in Shipbuilding Industry", Journal of the Ergonomics Society of Korea, 30(1), 127-135, 2011

KOSHA, Development of Audit Model for the Result of Hazard Assessment in Shipbuilding Industry, Korea Occupational Safety \& Health Agency, Technical Report, 2008-101-1256, 2008.

Ministry of Knowledge Economy, Knowledge economy white book 2008 2009, Ministry of Knowledge Economy, 2008-2009.

Ministry of Employment and Labor, Industrial accident analysis, Ministry of Employment and Labor, 2001-2010.

Pusan center of KOSHA, The present state of accident and hazardous and dangerous factors in shipbuilding process, The case study of major 7 shipbuilding company, Pusan center of Korea Occupational Safety $\&$ Health Agency, 2006, 2.

The Society of Naval Architects of Korea, Shipbuilding Terminology
Dictionary, The Society of Naval Architects of Korea, Munundang, 1997.

\section{Author listings}

Kyung Tae Lee: ktlee@db.ac.kr

Highest degree: PhD, Department of Industrial Engineering, KAIST Position title: Professor, Department of Management, Daebul University Areas of interest: Job Design, HCI, Human Factors in management

Date Received : 2012-01-05

Date Revised :2012-01-16

Date Accepted : 2012-01-17 